\title{
Synaptic Integration in Striate Cortical Simple Cells
}

\author{
Judith A. Hirsch, ${ }^{1}$ José-Manuel Alonso, ${ }^{1}$ R. Clay Reid, ${ }^{2}$ and Luis M. Martinez ${ }^{1}$ \\ 1'Laboratory of Neurobiology, The Rockefeller University, New York, New York, and '2Department of Neurobiology, \\ Harvard Medical School, Boston, Massachusetts
}

\begin{abstract}
Simple cells in the visual cortex respond to the precise position of oriented contours (Hubel and Wiesel, 1962). This sensitivity reflects the structure of the simple receptive field, which exhibits two sorts of antagonism between on and off inputs. First, simple receptive fields are divided into adjacent on and off subregions; second, within each subregion, stimuli of the reverse contrast evoke responses of the opposite sign: push-pull (Hubel and Wiesel, 1962; Palmer and Davis, 1981; Jones and Palmer, 1987; Ferster, 1988). We have made whole-cell patch recordings from cat area 17 during visual stimulation to examine the generation and integration of excitation (push) and suppression (pull) in the simple receptive field. The temporal structure of the push reflected the pattern of thalamic inputs, as judged by comparing the intracellular cortical responses to extracellular recordings made in the lateral geniculate nucleus.
\end{abstract}

Cortical sensitivity to patterned stimuli has its roots in the arrangement of synaptic inputs to simple cells, whose receptive fields are made of elongated, alternating on and off subregions. Bright signals confined to an on subregion are excitatory, whereas dark ones reduce activity; that is, stimuli of the opposite contrast have a push-pull effect (Hubel and Wiesel, 1962; Movshon et al., 1978; Heggelund, 1981, 1986; Palmer and Davis, 1981; Jones and Palmer, 1987; Ferster, 1988; Miller, 1994; Troyer et al., 1998; but see Debanne et al., 1998). Furthermore, when the receptive field is uniformly illuminated or darkened, simple cells respond poorly because their subregions have a mutually antagonistic relationship (Hubel and Wiesel, 1962). Thus, the output of the simple cell relies on the balance of excitation and suppression that various stimuli evoke.

We have used the technique of whole-cell recording (Hamill et al., 1981; Edwards et al., 1989; Blanton et al., 1989) in vivo (Pei et al., 1991; Ferster and Jagadeesh, 1992) to analyze the synaptic mechanisms that produce visually evoked responses in the receptive field. First, we examined the origins of excitatory and suppressive components of the responses to stimuli of reverse contrast flashed within a single subregion. Then we asked how

Received May 28, 1998; revised Aug. 27, 1998; accepted Aug. 28, 1998.

This work was supported by National Institutes of Health Grants EY09593 (J.A.H.) and EY05253 (T.N.W.), the Klingenstein Fund (J.A.H., R.C.R.), and the Human Frontiers Science Program Organization (L.M.M.). We are grateful to Torsten N. Wiesel for support and guidance during all phases of the project. Christine A. Gallagher, Kathleen McGowan, Johanna L. Kornblum, and Komal A. Desai provided superb technical support and drew the labeled cells, which Peter Peirce photographed precisely. We thank Sanford M. Simon for improving the manuscript, Matteo Carandini for advice in analyzing conductance changes, and S. Murray Sherman for helpful criticism of an earlier draft.

Correspondence should be addressed to: Judith A. Hirsch, Box 138, Laboratory of Neurobiology, The Rockefeller University, 1230 York Avenue, New York, NY 10021.

Copyright (C) 1998 Society for Neuroscience $\quad 0270-6474 / 98 / 189517-12 \$ 05.00 / 0$
Two mechanisms have been advanced to account for the pullwithdrawal of thalamic drive and active, intracortical inhibition (Hubel and Wiesel, 1962; Heggelund, 1986; Ferster, 1988). Our results suggest that intracortical inhibition is the dominant, and perhaps sole, mechanism of suppression. The inhibitory influences operated within a wide dynamic range. When inhibition was strong, the membrane conductance could be doubled or tripled. Furthermore, if a stimulus confined to one subregion was enlarged so that it extended into the next, the sign of response often changed from depolarizing to hyperpolarizing. In other instances, the inhibition modulated neuronal output subtly, by elevating spike threshold or altering firing rate at a given membrane voltage.

Key words: visual cortex; patch recording in vivo; simple cell; IPSP; EPSP; spiny stellate cell excitatory and suppressive mechanisms interact when engaged together, as happens when a stimulus tilts away from the axis of the field to span neighboring subregions. Although suppression might result either from the removal of excitation or from active inhibition, the findings of these studies stress that active inhibition in the cortical receptive field is strong and modulates excitatory input both by means of hyperpolarization and increasing the membrane conductance (Hirsch et al., 1995).

\section{MATERIALS AND METHODS}

Anesthesia. Adult cats, $2.5-3.5 \mathrm{~kg}$, were anesthetized with ketamine (10 $\mathrm{mg} / \mathrm{kg}$, i.m.) followed by thiopental sodium $(20 \mathrm{mg} / \mathrm{kg}$, i.v. $)$, supplemented as needed. Lidocaine was applied topically at all incisions or points of pressure. Temperature $\left(37-38^{\circ} \mathrm{C}\right), \mathrm{EKG}, \mathrm{EEG}$, and expired $\mathrm{CO}_{2}(27-33 \mathrm{mmHg})$ were monitored throughout the experiment. Anesthesia was maintained by a continuous infusion of thiopental sodium $\left(2-4 \mathrm{mg} \cdot \mathrm{kg}^{-1} \cdot \mathrm{hr}^{-1}\right.$, i.v.) adjusted as indicated by the EEG and EKG. After the completion of surgery, animals were paralyzed [vecuronium bromide (Norcuron) $0.2 \mathrm{mg} \cdot \mathrm{kg}^{-1} \cdot \mathrm{hr}^{-1}$, i.v.] and artificially respired.

Surgery. An endotracheal tube was introduced through a tracheotomy before the animal was placed in a stereotaxic apparatus. Two cortical craniotomies were made; one centered on Horsley-Clark coordinates A6.5-L8.5 gave access to the lateral geniculate nucleus, and the other, centered on Horsley-Clark P3-L2, was enlarged to expose the longitudinal gyrus. Pupils were dilated with $1 \%$ atropine sulfate, and the nictitating membranes were retracted with $10 \%$ phenylephrine. Eyes were refracted and fitted with contact lenses to focus on a tangent screen. The position of the area centralis and the optic disk of each eye was determined with a fundus camera.

Acquisition of visually evoked responses. Intracellular and extracellular records were collected by a computer running the Discovery software package (Datawave Systems, Longmont, CO), intracellular records were normally sampled at 3-4 kHz. Each recording session was also stored on videotape at $11-22 \mathrm{kHz}$. An AT-vista board (Truevision, Indianapolis, IN), controlled by the same computer that received the data generated visual stimuli that were presented on a computer monitor (frame rate $100,105,128$, or $140 \mathrm{~Hz}$ ). Each cycle of the stimulus protocol consisted of light or dark squares at various contrasts (range, 30-70\%) flashed 
singly for 29-39 msec in pseudorandom order, 16 times on a $16 \times 16$ grid (sparse noise; see Jones and Palmer, 1987). Grid spacing ranged from 0.4 to $0.85^{\circ}$ and square size from 0.4 to $1.7^{\circ}$. Although there was no delay between sequential stimuli (as one was switched off another was flashed on), effective squares were usually separated by substantial intervals because the receptive fields were typically much smaller than the stimulus grid. Maps of the receptive fields were made by subtracting responses to dark stimuli from responses to bright stimuli and are plotted as shaded contours; each successive concentric line indicates a $10 \%$ reduction in the strength of response relative to the peak (spikes inclusive). Receptive fields with separate and adjacent on and off subregions were classified as simple (Hubel and Wiesel, 1962; for review, see Skottun et al., 1991). The terms on and off are equivalent to the terms brightexcitatory and dark-excitatory used by others (DeAngelis et al., 1992).

Recording. Patch-pipette resistance was $\geq 12 \mathrm{M} \Omega$ when filled with internal solution, in $\mathrm{mM} ; \mathrm{K}$ gluconate $120 ; \mathrm{NaCl} 5 ; \mathrm{CaCl}_{2} 1 ; \mathrm{MgCl}_{2} 1$; EGTA 11; GTP 0.2; ATP 2; HEPES 40; and biocytin 1\%, pH 7.3, 290 mOsm (Malinow and Tsein, 1990). For three cells, $10 \mathrm{mM}$ QX-314 Br (courtesy of Astra) was included in the pipette. Initial seal resistances were 0.5-1.0 G $\Omega$. Recordings were made with an Axopatch 200a amplifier and stored as described above; neither capacitance nor access resistance was compensated, so fast events were filtered. The bridge was balanced off-line. The voltage-current relationship was measured before and after each cycle of the stimulus protocol to monitor changes in the access and apparent input resistance, threshold for firing, and membrane time constant. The DC voltage changes produced by constant current injection during a given cycle of the protocol were taken from the responses to equivalent current pulses delivered before or after the cycle. This procedure served to separate drift in the recording circuit from real changes in the membrane potential that may have occurred over time. Because the access resistance often increased after rupture of the membrane (Edwards and Konnerth, 1992), the voltage in the records was sometimes divided (Stühmer et al., 1983). For this reason, as well as drift that can occur over the long time courses of the recording, we do not provide absolute resting potentials. Extracellular recordings in the lateral geniculate were amplified, filtered, and collected in parallel with the intracellular recordings.

Histology. After histological processing (Horikawa and Armstrong, 1988; Hirsch, 1995) labeled neurons were drawn using a camera lucida, or a computerized three-dimensional reconstruction system, (Microbrightfield, Cochester, VT). Reconstruction of the electrode tracks revealed that, with the exception of two dendritic recordings, our recordings came from the soma.

\section{RESULTS}

We have recorded from 21 simple cells in the adult cat striate cortex. Intracellular labeling allowed us to identify many of the cells from which we recorded; our sample included four layer 6 pyramids, four pyramids at the borders of layer 4 , and nine spiny stellate cells in layer 4 . Recordings lasted from $20 \mathrm{~min}$ to $2.75 \mathrm{hr}$, normally $30 \mathrm{~min}$ to $1 \mathrm{hr}$. The average time constant of the cells was $21 \pm 4.2 \mathrm{msec}$ (range, 15-24 msec). In addition, we have recorded extracellularly from fifteen cells in the lateral geniculate nucleus and measured their responses to the same set of visual stimuli used to study cortex.

\section{Synaptic construction of the receptive field}

Flash-evoked responses in the simple receptive field

Simple cells responded to the sparse-noise stimulus in a stereotyped way. Figure 1 shows the synaptic responses to light and to dark stimuli that fell over the peak of the off or the on subregion. The inset over each panel shows the stimulus position in the receptive field (the off subregion is depicted as concentric bands that grow darker toward the peak; likewise, the on subregion is mapped by contours whose shade lightens as the strength of response increases). Each set of traces shows two individual responses to the stimulus and, beneath these, the averaged responses of all sixteen trials. A dark square presented to the middle of the off subregion evoked an initial depolarization capped by a train of action potentials. The subsequent hyperpo- larization and weak depolarization corresponded to the withdrawal of the dark square (cf. Ohzawa et al., 1996). Accordingly, a light square flashed at the same site evoked a hyperpolarization followed by a depolarizing wave. The responses evoked from the on subregion qualitatively mirrored those elicited from the off subregion. Superimposed on this basic structure, each simple cell had its own distinct behavior. For example, for the neuron illustrated here, responses to dark stimuli were stronger than responses to bright ones. Small variations aside, the push-pull response to squares flashed within a given subregion was common to all cells, provided the resting potential was near the threshold for firing.

Comparison of the duration of thalamic and cortical responses Simple cells receive the bulk of the input from the lateral geniculate nucleus (Lorente de Nó, 1944; Hubel and Wiesel, 1962; LeVay and Gilbert, 1976; Humphrey et al., 1985; Peters and Payne, 1993). To understand better how the primary afferents influence simple cells, we recorded extracellularly from the lateral geniculate during presentation of the sparse noise stimulus. Then we compared the histograms of thalamic activity with the intracellular cortical responses (Table 1). The cortical depolarization evoked by a stimulus of the appropriate sign (onset excitation) peaked while the relay cells were firing (onset activity). Likewise, withdrawal of a stimulus of the opposite sign produced an excitatory response in cortex (offset excitation) that followed the course of thalamic activity (offset activity). The complementary hyperpolarizing phases of the response also tracked thalamic firing, but had longer delays $(2-10 \mathrm{msec})$ than the excitatory components, consistent with a synaptic relay through inhibitory interneurons (see next section of Results). In general, the cortical responses differed from the envelopes of thalamic activity in having somewhat longer durations. The prolongation of cortical responses may have been produced variously by the passive and active properties of the membrane (Rall, 1977; Hirsch, 1995), input from lagged relay cells (not included in our sample) (Mastronarde, 1987; Humphrey and Weller, 1988; Cai et al., 1997), and intracortical synaptic inputs (McGuire et al., 1984; Saint-Marie and Peters, 1985; Douglas et al., 1991; Peters and Payne, 1993; Ahmed et al., 1994; Hirsch, 1995; Cai et al., 1997).

\section{Mechanisms of inhibition in the simple receptive field}

Two distinct mechanisms, one passive and one active, are thought to contribute to the stimulus-evoked suppression. The idea of a passive contribution stemmed from the observation that cells in the lateral geniculate nucleus have high rates of spontaneous activity (Hubel and Wiesel, 1961) and are excitatory (LeVay and Gilbert, 1976; Hoffman and Stone, 1971; Ferster and Lindström, 1983; Hagihara et al., 1988). Thus, they could contribute a tonic depolarizing component to the resting potential of the simple cell membrane (Hubel and Wiesel, 1962). Presentation of a stimulus of the unmatched sign would lead to a dip in the transmembrane voltage of a simple cell as a consequence of silencing excitatory inputs from the thalamus. Active inhibition could be accounted for by cortical interneurons driven by thalamic afferents (Hubel and Wiesel, 1962; Sillito, 1975; Gilbert and Wiesel, 1979; Heggelund, 1986; Palmer and Davis, 1981; Jones and Palmer, 1987; Ferster, 1988).

We conducted experiments to examine the relative contributions of these active and passive mechanisms. Postsynaptic inhibition would be reflected by an increase in the membrane conductance, whereas the passive mechanism, withdrawal of 


\section{A) Responses from the off subregion}
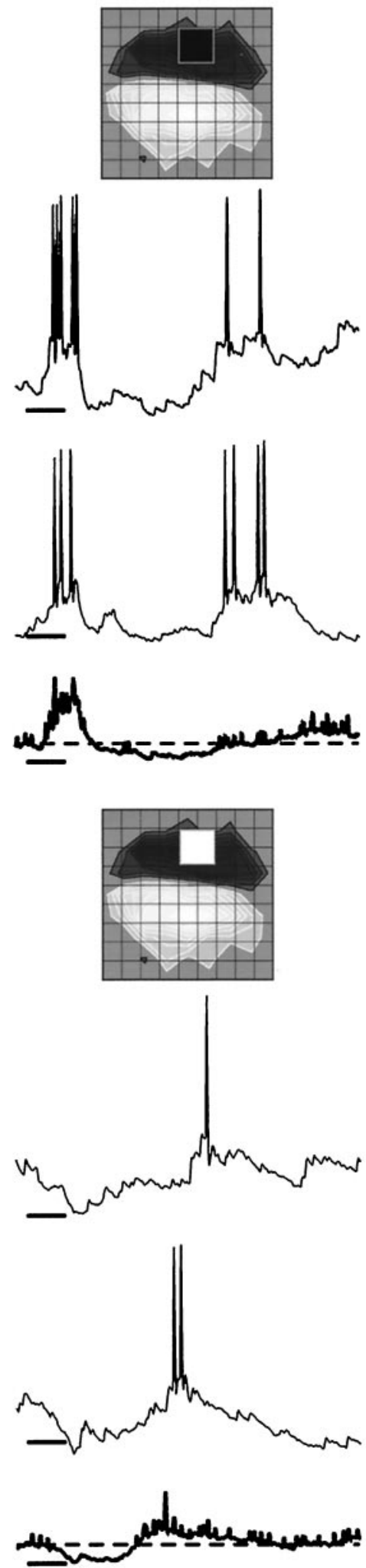

\section{B) Responses from the on subregion}
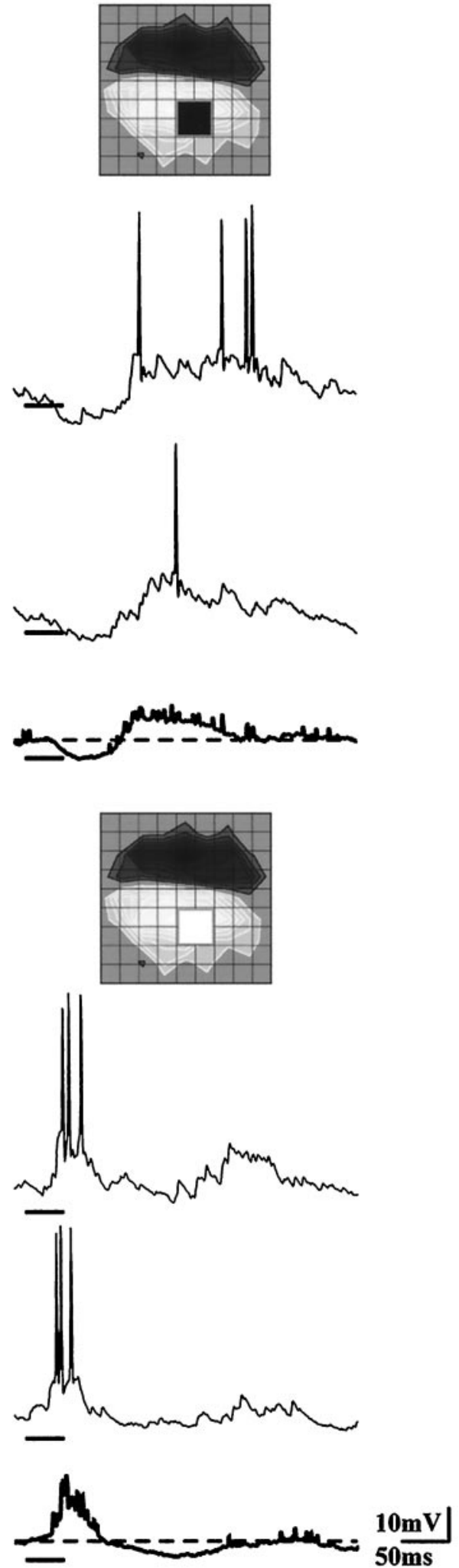

Figure 1. Push and pull in the simple cell response. Postsynaptic responses evoked by dark or bright stimuli that fell inside the off or the on subregion of a simple cell in upper layer 6. Each panel shows two individual responses to the stimulus with the average of all 16 as the bold trace beneath. The position and sign of the stimulus is indicated in the receptive field map (the peak of the on subregion is light and that of the off subregions is dark; grid spacing is $0.4^{\circ}$ ) above each panel. Stimulus duration is marked by the bold bar under each trace in this and subsequent figures. $A$, A dark square flashed in the off subregion elicited an initial depolarization and late hyperpolarization, top, whereas a bright square at the same site evoked a hyperpolarization and subsequent depolarization, bottom. B, Responses from the on subregion mirror those from the off. 
Table 1. Temporal substructure of cortical and thalamic responses to stimuli of reverse contrast

Simple cells

Push

\begin{tabular}{llllll}
\hline Latency & Duration & Peak & & Latency & Duration \\
\hline 28 & 62 & 36 & 90 & 120
\end{tabular}

239

$28 \quad 62$

$30 \quad 50$

$28 \quad 82$

$22 \quad 60$

$20 \quad 85$

$19 \quad 41$

$20 \quad 102$

$20 \quad 53$

$23.8 \pm 4.2 \quad 66.6 \pm 18.4 \quad 34.4 \pm 5.5$

$\begin{array}{rr}90 & 120 \\ 92 & 133 \\ 90 & 65 \\ 80 & \end{array}$

80

110

82

105

60

122

73

$90.4 \pm 18.2 \quad 147 \pm 84.6$

Pull

Onset suppression

Latency Duration Latency Duration

$\begin{array}{lll}38 & 74 & 112 \\ 32 & 80 & 112\end{array}$

32

29

38

38
28

28
24

22

30

23

25

$28.9 \pm 5.8$
80

71

52

68

61

73

70

69

85

$70.3 \pm 9.2$

112
100

100
90

85

95

100

92
96

110

$99.2 \pm 97.2165 .9 \pm 67.9$

\begin{tabular}{|c|c|c|c|}
\hline \multicolumn{2}{|l|}{ Push } & \multicolumn{2}{|l|}{ Pull } \\
\hline \multicolumn{2}{|c|}{ Onset activity } & \multicolumn{2}{|c|}{ Offset activity } \\
\hline Latency & Duration & Latency & Duration \\
\hline 24 & 37 & 111 & 31 \\
\hline 23 & 23 & 110 & 68 \\
\hline 19 & 28 & 64 & 119 \\
\hline 18 & 22 & 87 & 67 \\
\hline 18 & 22 & 81 & 15 \\
\hline 20 & 27 & 92 & 34 \\
\hline 24 & 20 & 108 & 19 \\
\hline 27 & 30 & 100 & 27 \\
\hline 25 & 27 & 100 & 69 \\
\hline 22 & 27 & 72 & 54 \\
\hline
\end{tabular}

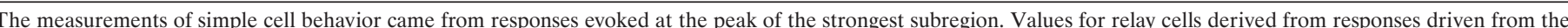

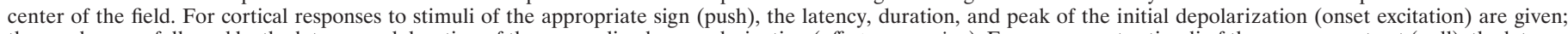

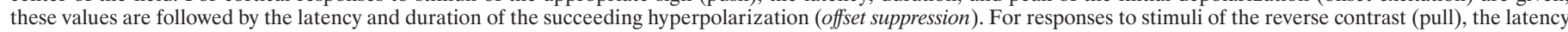

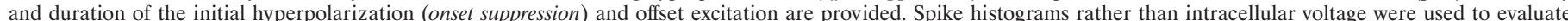

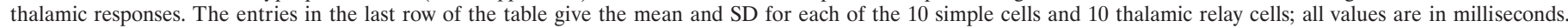

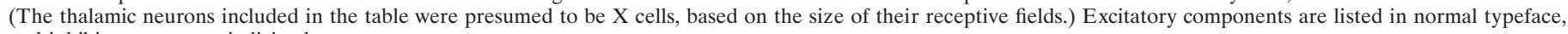
and inhibitory ones are italicized.

excitation, would reduce conductance. Furthermore, the shape of a waveform produced by active process would shrink and then reverse sign as the membrane voltage neared and then moved below the reversal potential of the IPSP ( $\left.E_{I P S P}\right)$. By contrast, hyperpolarization would emphasize a withdrawal component because the membrane would be moved farther way from the reversal potential for excitation ( $\left.\mathrm{E}_{\mathrm{EPSP}}\right)$.

One series of experiments evaluated changes in the membrane resistance during the visually evoked hyperpolarization. For the spiny stellate cell drawn in Figure $2 A$, the membrane conductance nearly doubled during the response to a stimulus of the inappropriate contrast. A dark stimulus presented to the on subregion produced a robust hyperpolarization; Figure $2 B$ shows three individual trials of stimulus and the averaged response in bold. Figure $2 C$, bottom compares the averaged response at the control voltage (bold line) with the averaged response to the same stimulus presented while the membrane was held at a relatively hyperpolarized level (dotted trace). These two responses, obtained at two different holding currents, allowed measurement of the change in conductance during the response, $g(t)$ (Fig. 2C, top). The conductance as a function of time was calculated as,

$$
g(t)=K\left(I_{\mathrm{p}}-I_{\mathrm{n}}\right) /\left(V_{\mathrm{p}}(t)-V_{\mathrm{n}}(t)\right)
$$

where $I_{\mathrm{p}}$ is the amount of current injected through the electrode during the control (relatively depolarized) recording and $I_{\mathrm{n}}$ is the more hyperpolarized constant current, $V_{\mathrm{p}}(t)$ and $V_{\mathrm{n}}(t)$ are the membrane voltages at these two holding currents, and $t$ is the time before, during, and after stimulus presentation. The constant $K$ normalized the conductance so that $g(0)=100 \%$. Figure 3 charts the change in membrane conductance for three other cells. Typically, the change in conductance evoked was between 200 and $300 \%$. The top two traces come from recordings made when QX-314 was present in the recording electrode. Because QX-314 blocks the slow, potassium-mediated IPSP (Otis et al., 1993), it is likely that that much of the conductance increase is caused by the fast, chloride-mediated IPSP.
We evaluated the relative importance of active and passive processes in generating the visually evoked suppression by determining the voltage dependence of the response to stimuli of the inappropriate contrast. The morphology of a spiny stellate cell in which the visually evoked suppression was reversed is illustrated in Figure 4, top. The soma was located in the middle of layer 4; the axon projected to the lower half of layer $2+3$ and to layer 6 . Each panel in this figure shows somatic recordings made when the membrane was held at different levels of polarization. While the membrane was depolarized with current, the stimulus evoked a prominent hyperpolarization (Fig. 4B). When a moderate amount of hyperpolarizing current was injected, the initial response was slight if visible at all (Fig. 4C). Finally, the application of a stronger current changed the sign of the response from hyperpolarizing to depolarizing (Fig. 4D). Of five cells tested, the IPSP was fully reversed in two. In the remaining cells, for suppression evoked by the flashed squares or by moving bars, the equilibrium potential was reached but the recordings ended before the next opportunity to inject stronger currents. All told, these results indicate that intracortical inhibition was the dominant force in generating suppressive responses evoked by stimuli of the opposite contrast; slight contributions made by the withdrawal of tonic excitation might have been present but masked by active processes.

\section{Interactions between and excitation and inhibition in simple cells}

To examine the interactions between excitation and inhibition we used stimuli large enough to span the border between subregions, Figure 5. The receptive field of the cell, a layer 6 pyramid (Fig. $5 E$ ), had a strong on subregion and a weaker off subregion. A small stimulus confined to the off subregion evoked a strong depolarization (Fig. 5A, left column). The response to a larger stimulus that spread into a portion of the neighboring on subregion was hyperpolarizing (Fig. $5 A$, right column). These results indicated that the excitation evoked from the off subregion was 


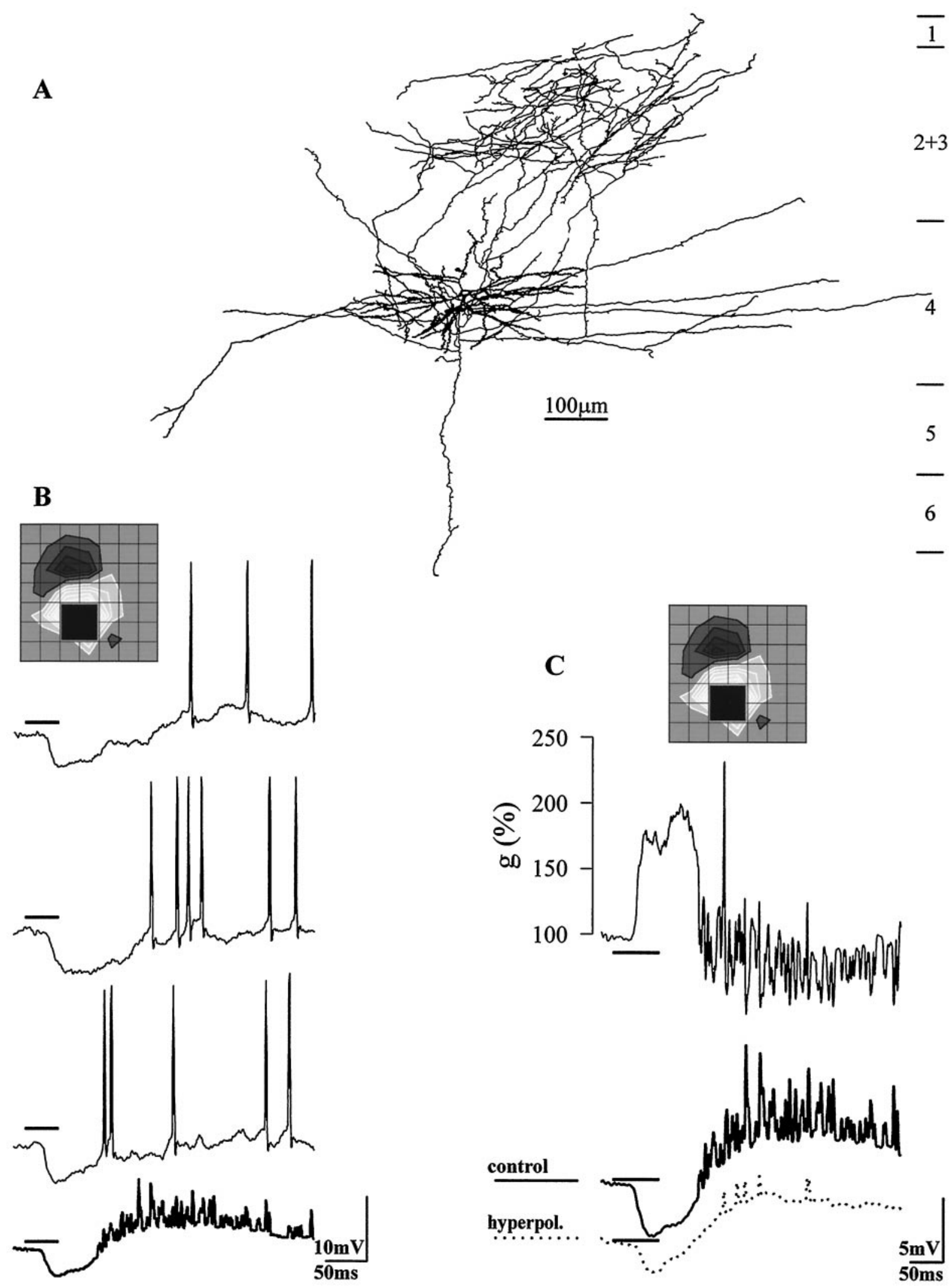

Figure 2. Visually evoked suppression is accompanied by an increase in the membrane conductance. $A$, Reconstruction of the cell, a spiny stellate cell in layer 4. $B$, A dark square flashed within the on subregion evoked a brisk hyperpolarization, as shown in three individual trials of the stimulus and the average of sixteen trials (bold). C, Top trace, Plot of conductance during the visual response: $g(t)=K\left(I_{\mathrm{p}}-I_{\mathrm{n}}\right) /\left(V_{\mathrm{p}}(t)-V_{\mathrm{n}}(t)\right)$; $g(t)$ is the normalized conductance at time $t, I_{\mathrm{p}}-I_{\mathrm{n}}$ is the difference between the values of constant current injected through the electrode, and $V_{\mathrm{p}}(t)$ and $V_{\mathrm{n}}(t)$ are the membrane voltages recorded while the membrane was held at the relatively positive and negative levels. The averaged responses obtained at the control and hyperpolarized levels that were used to calculate $g(t)$ are shown below the graph. Grid spacing was $0.85^{\circ}$. 
A

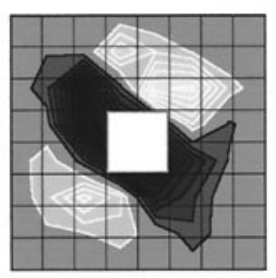

B

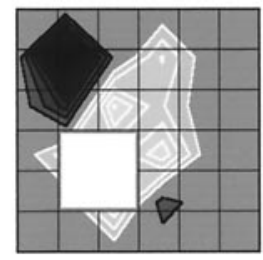

C

Figure 3. The time course of conductance increase during visually evoked suppression in three simple cells. $A, B$, Records from two layer 4 spiny stellate cells recorded with QX-314 in the electrode (the receptive field of cell $B$ fell slightly outside of the stimulus grid). $C$, Record from a pyramid at the upper border of layer 4 . Grid spacing: $A, B, 0.85^{\circ} ; C, 0.4^{\circ}$.
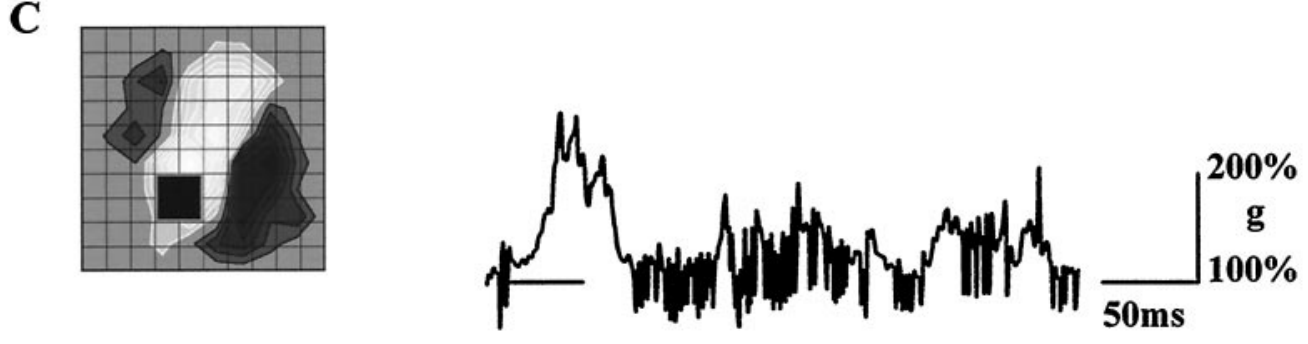

overwhelmed by the inhibition elicited from the on subregion. Similar interactions were observed in eight cells recorded when the membrane potential was near the threshold for firing. A wiring diagram illustrating a circuit that could mediate this interaction is shown in Figure $5 F$. The large and small stimuli are sketched over the fields of two adjacent off-center relay cells that provide input to a pair of inhibitory and excitatory simple cells. The receptive fields of the two simple cells overlap but have an inverse arrangement of on and off subregions. The smaller size of the on subregion of the inhibitory simple cell indicates that this subregion is weaker than the off, a feature that would account for that fact that the cell is well driven by the large, dark stimulus.

An alternative possibility to explain the suppressive response is that the larger square drove fewer thalamic spikes than the smaller one because the bigger stimulus invaded the suppressive surrounds of the relay cells. Hence, the response to the large spots might reflect this reduced excitatory input to the cortex. The records in panels Figures $5 B-D$ provide two lines of evidence that reduction in thalamic drive does not account for our observations.

The average response to the large dark spot, recorded at the control level of membrane polarization, was plotted beside the averaged response to the same stimulus presented while the membrane was slightly hyperpolarized (Fig. 5B). At the hyperpolarized potential, the membrane was nearer $\mathrm{E}_{\text {IPSP }}$ and farther from $E_{\mathrm{EPSP}}$, reducing inhibitory effects while en-
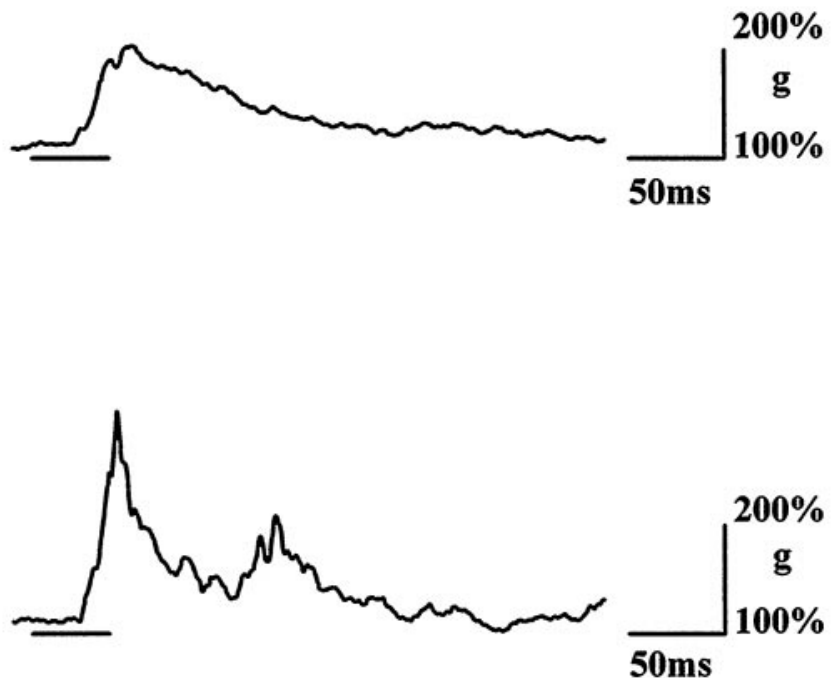

$50 \mathrm{~ms}$

hancing excitatory currents. At this hyperpolarized potential, a strong excitatory component of the response was revealed. Thus, nearer the threshold for firing, although the net response to the overlapping stimulus was inhibitory, it did contain a strong excitatory component. A remaining question was whether or not the depolarization evoked by the large stimulus was really a reversed IPSP? Figure $5 C$ shows responses to large bright and dark squares that covered the off subregion and spilled outside of the receptive field. The response to bright stimuli flashed within the off subfield evoked a well defined hyperpolarization; the recording had remained above $\mathrm{E}_{\mathrm{IPSP}}$.

As described earlier, we often place extracellular electrodes in the lateral geniculate nucleus in addition to the patch pipette in cortex. These recordings have provided additional evidence that the large spots did not lead to suppression of geniculate input. Figure $5 D$ shows the receptive field of an off center thalamic cell mapped with the small stimulus (left) and the large one (right). The receptive field of the relay cell was located at the upper border of the simple field. Plots of spike rate over time beneath each map show that the large spots were slightly more, rather than less, effective in driving thalamic activity. This occurred even though the large spot fell mainly outside of the center of the thalamic receptive field. In fact, we have not yet seen an instance in which the large spots evoke less activity than the small ones. Our sample contains over 10 similar records and includes exam- 

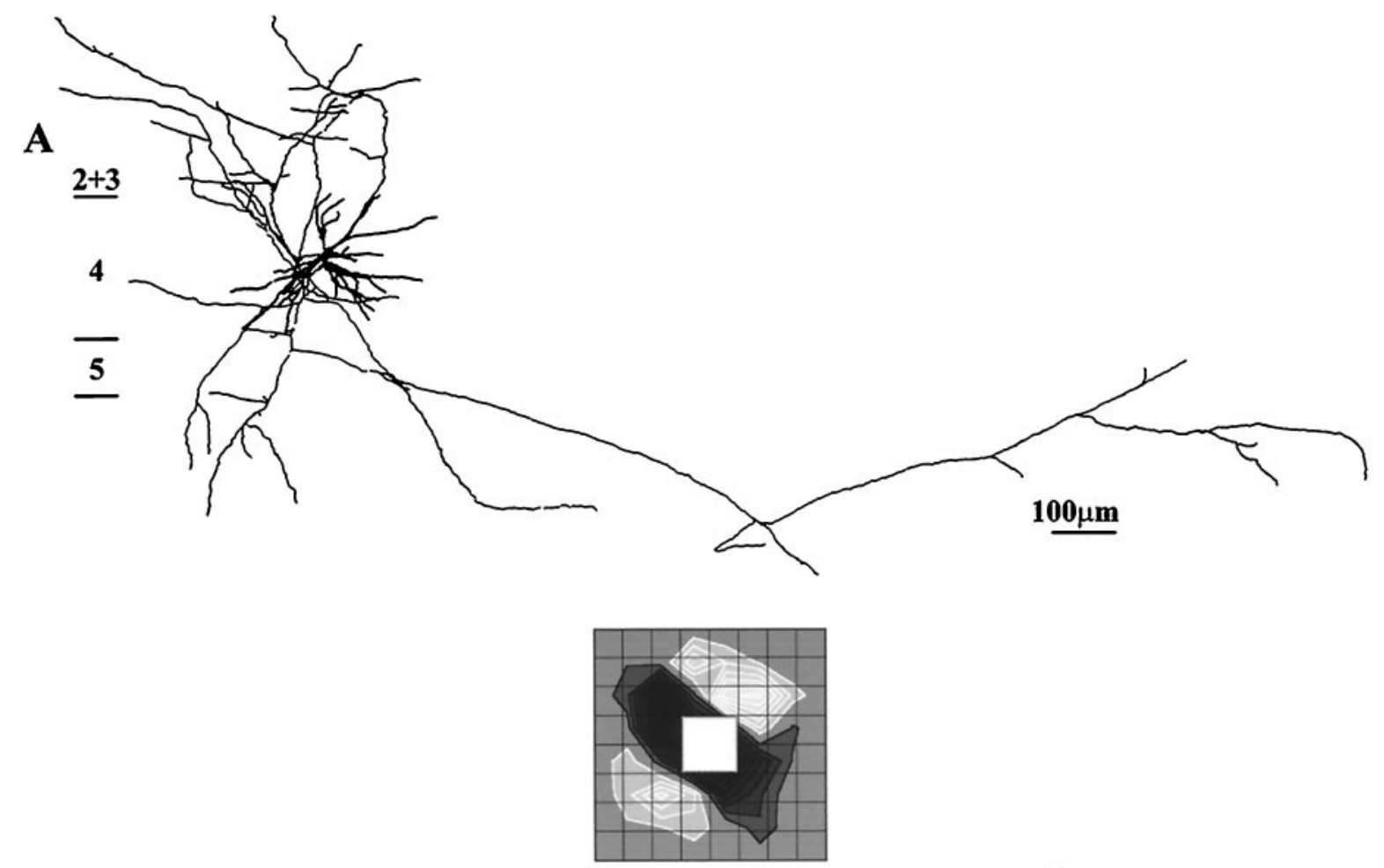

B moderately depolarized $+0.4 \mathrm{nA}$

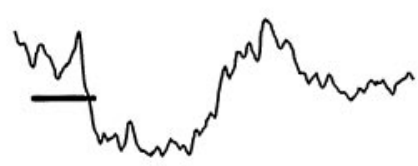

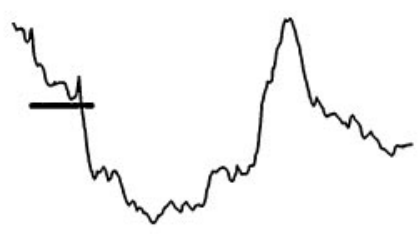

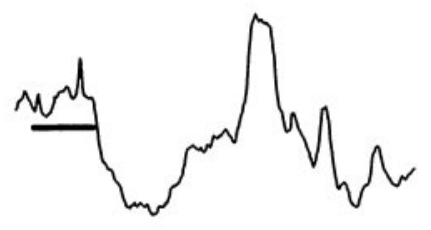

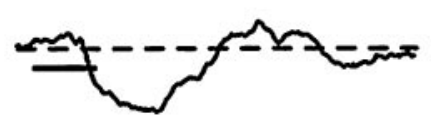

\section{C} moderately hyperpolarized

$-0.3 \mathrm{nA}$

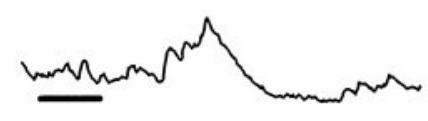

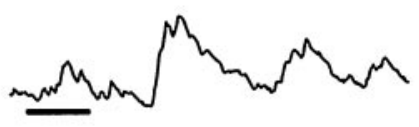

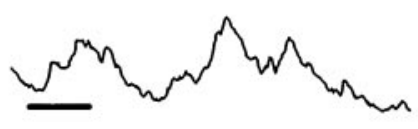

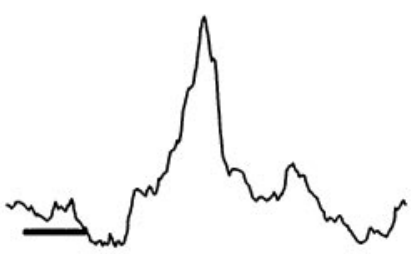

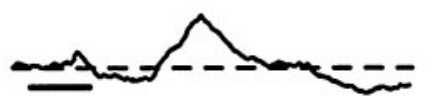

D strongly hyperpolarized

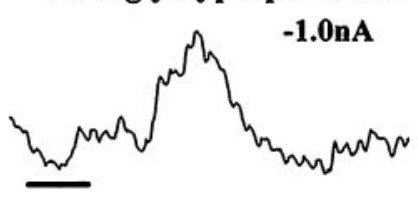

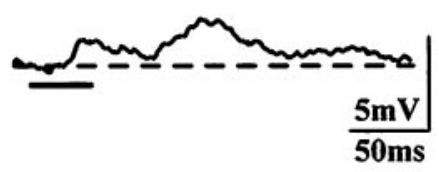

Figure 4. Reversal of the visually evoked suppression. Reconstruction of the cell, a spiny stellate cell in layer $4(A)$. Responses to a stimulus of the inappropriate polarity recorded while the membrane was held at three different levels of polarization. When the membrane was moderately depolarized, the initial response was hyperpolarizing $(B)$. When membrane potential was stepped to more hyperpolarized levels, the response amplitude diminished $(C)$, and then reversed $(D)$. Recordings were actually collected in the order $C, B, D$; action potentials were suppressed with $10 \mathrm{~mm}$ QX-314. Grid spacing was $0.85^{\circ}$. 


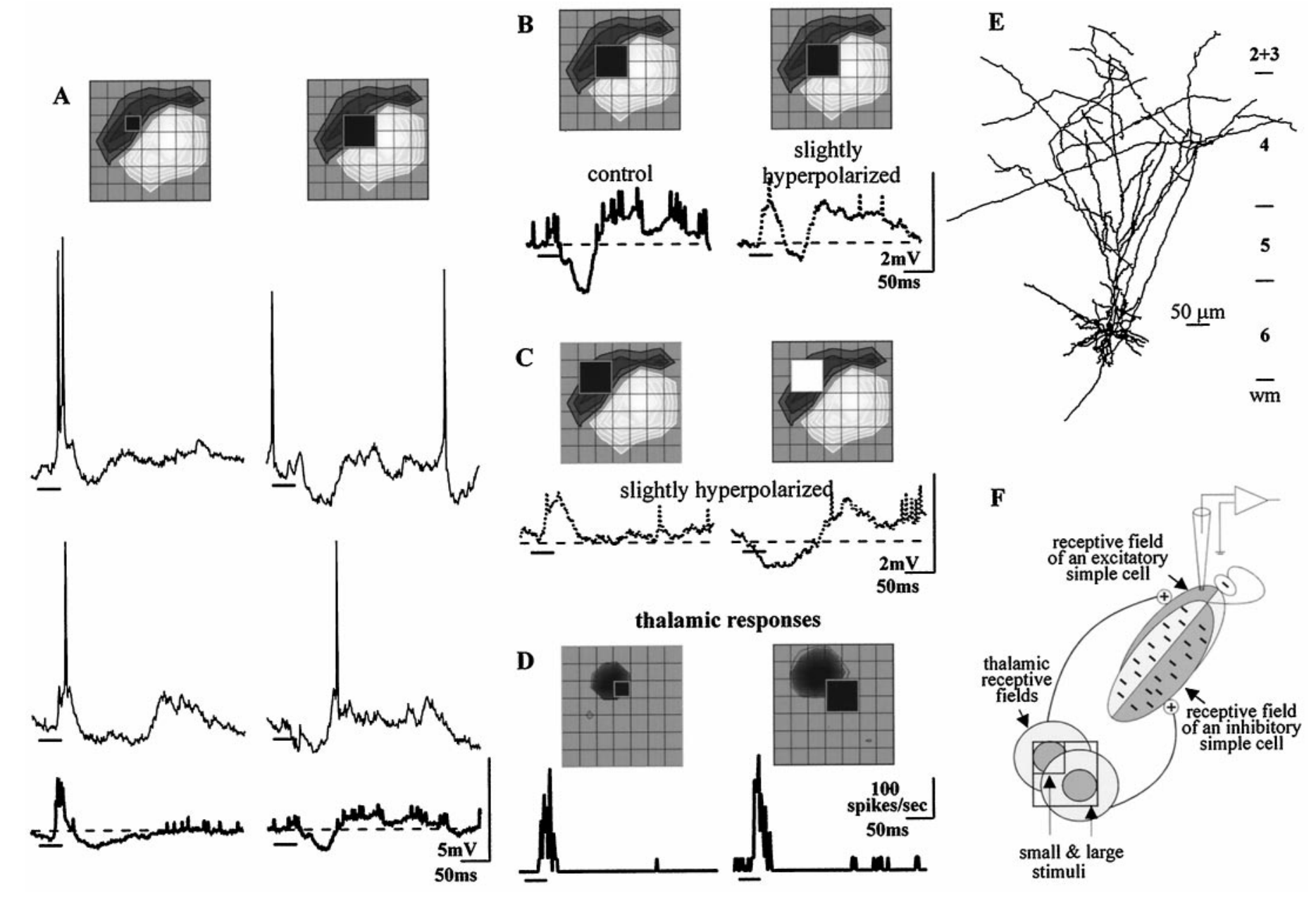

Figure 5. Antagonism between subregions in the simple receptive field. A, Left, A small dark square confined to the off subregion evoked a depolarization. Right, A larger stimulus that spread into the on subregion suppressed the excitation driven through the off subregion. $B$, The averaged response to the large square (as in $A$ ) shown beside the averaged response to an identical stimulus flashed while the membrane was slightly hyperpolarized. The inhibition that dominated the right trace suppressed the excitation visible in the left trace. C, Responses to large dark (left) and bright (right) squares that avoided the on subregion recorded while the membrane was at the hyperpolarized level. Left. The excitatory component of the response to the overlapping stimulus (i.e., $B$, right) matched the excitation evoked by the dark stimulus that fell inside the off subregion. Right, The response to the bright stimulus shows that the membrane voltage had remained above the reversal potential for inhibition. $D$, Receptive fields and poststimulus time histograms from an extracellularly recorded, off center LGN X cell monitored at the same time as the cortical simple cell. The large spot (right) drove more spikes than the small one did (left), although the large spot fell mainly outside the center. (The subsample of the stimulus grid for the simple cell is shifted down two pixels from that for the relay cell.) $E$, The cell was a pyramid in layer 6 . $F$, Possible circuit: the receptive field of superimposed inhibitory simple cell whose subregions are reversed compared with those of patched neuron, the fields of antecedent thalamic cells and relative stimulus placement. Grid spacing, $0.4^{\circ}$.

ples from both sizes of stimulus grid we use [cells were presumed to be $\mathrm{X}$ cells based on the relative size of the receptive field compared with nearby neurons (Alonso et al., 1996; Reid and Alonso, 1996)]. Our results are in keeping with earlier studies that found that a substantial amount of the surround must be recruited to reduce the firing from the center (Hubel and Wiesel, 1961; Cleland and Lee, 1985; Bullier and Norton, 1987). Presumably, the suppressive mechanisms that regulate the response would shift from active inhibition to thalamic withdrawal when larger stimuli that cover more of the surround are used.

The forms of subfield interaction we have described so far can be explained simply by the hyperpolarizing effects of inhibition. Other more subtle responses are consistent with a weak shunt, or veto, mechanism. Figure $6 A$ shows responses evoked by square that fell within the boundaries of a single subregion. On the right are responses to a stimulus that edged from this subregion into an adjacent one. While the initial depolarizations evoked by the cross-border stimulus were often larger than the ones produced by the confined square, they often failed to produce action potentials. The top trace shows a suprathreshold response, but the threshold voltage was higher than for the two impulses that followed in the late phase of the response. By contrast, although the depolarizations evoked from the home subregion were smaller, they drove spikes or trains of spikes. A similar situation held for the recording shown in Figure $6, C$ and $D$; that is, the threshold for firing in the response to the overlapping stimulus was higher. This difference in threshold coincided with a difference in firing rate. During the initial phase of the response depicted in the left records, 9 spikes were produced by the overlapping stimulus and 21 by the confined square, for the cell on the left, the ratio was 17:25. The two plots inset beneath the traces were constructed from responses to pulses of depolarizing current 
A
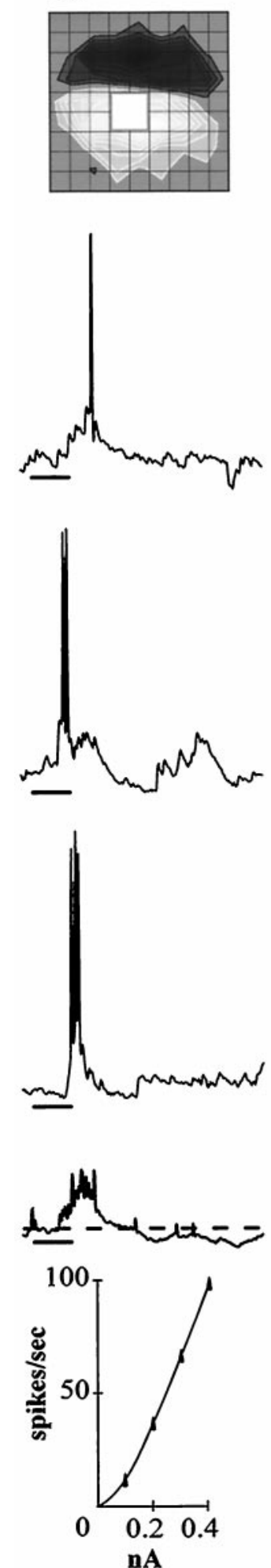

B
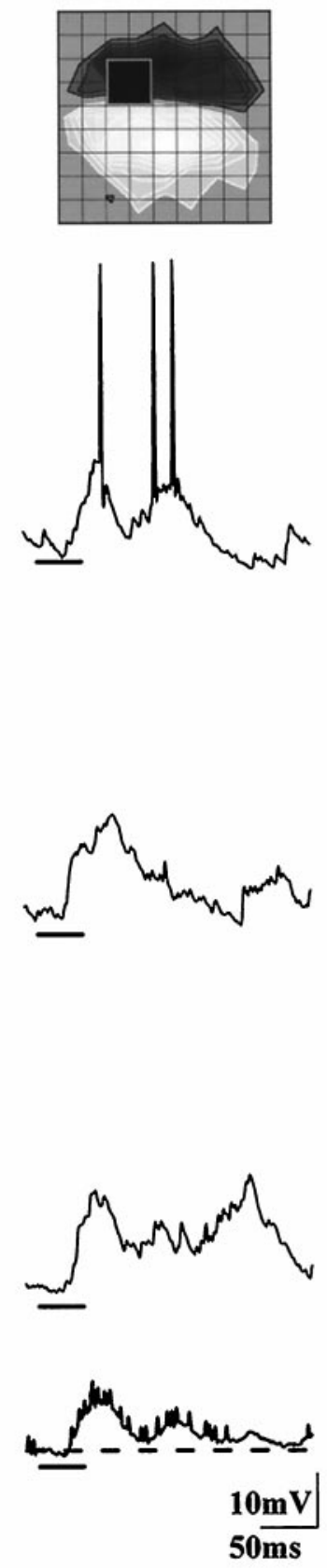

C
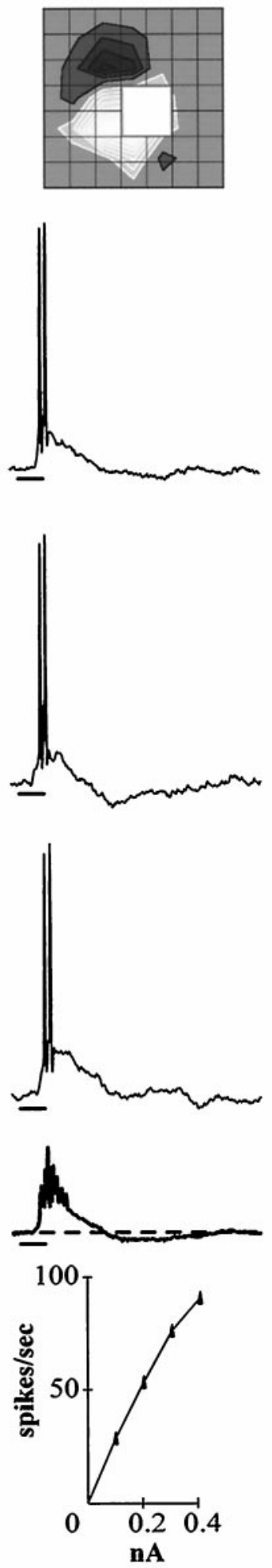

D
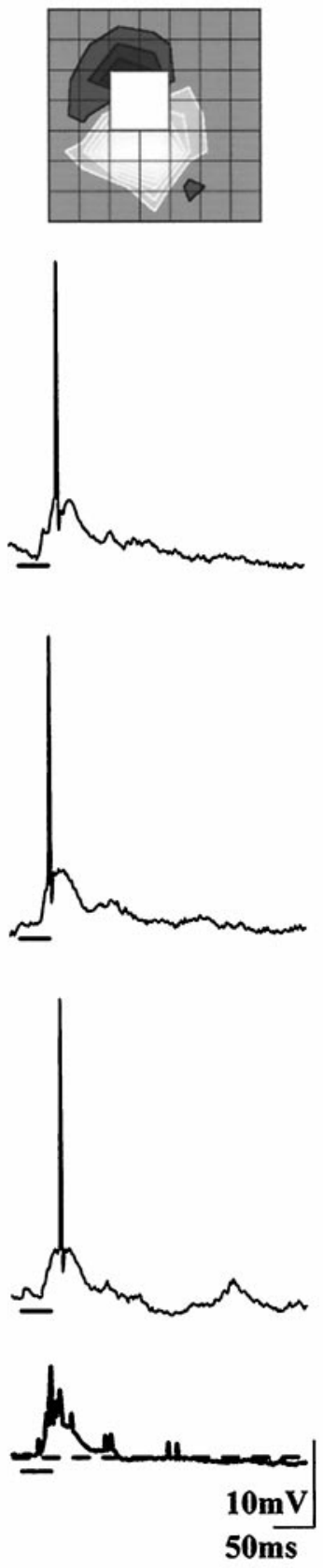

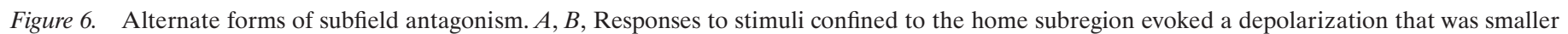

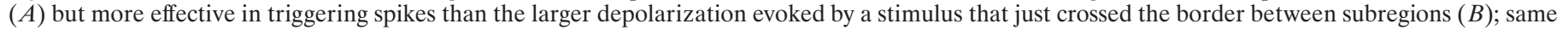

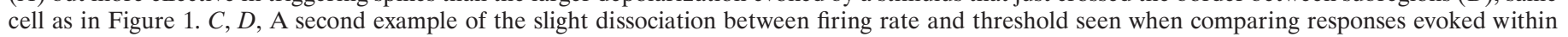

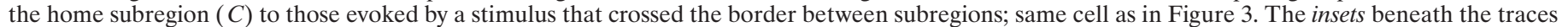
show that spike frequency increased monotonically with injection of direct depolarizing current pulses for each cell. 
injected through the electrode; they show that spike frequency increased with current strength. Hence, the dissociation between the synaptically induced voltage changes and firing rate is unlikely to reflect intrinsic properties of the neural membrane.

\section{DISCUSSION}

We have examined mechanisms of excitation and inhibition in the simple cells of the cat primary visual cortex. The temporal structure of the excitatory components of receptive field largely reflected thalamic drive, as judged by comparing thalamic firing patterns to the shape of the depolarizing components of the simple cell response. Active intracortical inhibition, on the other hand, appeared to play the dominant role in generating suppressive responses; suppression was accompanied by a substantial change in the membrane conductance and could be reversed when the membrane was hyperpolarized with current injected through the electrode. Thus, it seems that suppression must be mediated by inhibitory interneurons that contact cells whose subregions have the opposite polarity (Hubel and Wiesel, 1962; Palmer and Davis, 1981, Jones and Palmer, 1987; Ferster, 1988) rather than by reduction in the output of thalamocortical synapses. Furthermore, the dynamic range of inhibitory effects is wide. Inhibition can act powerfully, by summing with concomitant excitatory input to produce a net hyperpolarization, or it can act subtly by influencing firing threshold and rate.

\section{Mechanisms of inhibition Conductance changes}

Our results show directly that inhibition in the simple receptive field is strong (Sillito, 1975, 1992; Heggelund, 1986; Ferster, 1986, 1988; Bonds, 1989; DeAngelis et al., 1992; Volgushev et al., 1993; Nelson et al., 1994; Pei et al., 1994; Crook et al., 1997). We have found that the visually evoked suppression is accompanied by a twofold to threefold increase in the membrane conductance. It should be remembered, however, that our stimulus yielded modest responses compared with those that would be produced by oriented bars or gratings. Thus, conductance changes larger than those we have measured should occur routinely. Mechanistic models of normalization processes in cortex (Heeger, 1992; Carandini and Heeger, 1994; Carandini et al., 1997) such as the contrast gain control (Sclar and Freeman, 1982; Ohzawa et al., 1982) call for large, visually evoked changes in the membrane conductance, which, our results suggest exist.

The presence of a conductance increase was not unexpected (Bernander et al., 1991) and has been found in other systems. Blockade of spontaneous inputs to cortical pyramids increases the membrane resistance by $30-70 \%$ (Pare et al., 1998). In Purkinje cells, a train of spikes from just one presynaptic interneuron can reduce input resistance by a third (Häusser and Clark, 1997). Some earlier studies of the striate cortex did not detect changes in conductance during visual stimulation (Douglas et al., 1988; Berman et al., 1991; Ferster and Jagadeesh, 1992), although Ferster (1988) demonstrated an active cortical component of inhibitory interactions. These differences in measurement may have come about because some earlier tests were made from cells impaled with sharp electrodes, which themselves introduce a large resting leakage conductance (Staley et al., 1992) or from difficulties associated with the high access resistances involved in patch recording from tissue (Stühmer et al., 1983; Edwards and Konnerth, 1992).

\section{Independence of excitation and inhibition}

The visually evoked suppression could be reversed by current injection, suggesting that it is mediated by intracortical inhibition. A small part of an earlier study led to the conclusion that withdrawal of thalamic drive contributed strongly to visual responses (Ferster, 1988). In that study, thalamic afferents were electrically activated to produce a monosynaptic EPSP and disynaptic IPSP; at the resting potential, the shock-evoked response lacked a hyperpolarizing component so the resting potential was equated with $\mathrm{E}_{\text {IPSP. }}$ Visually driven hyperpolarizations from rest were taken to reflect thalamic withdrawal because active inhibition was thought to be silent. There are two concerns with this interpretation. First, it seems that the resting potential was actually above $\mathrm{E}_{\text {IPSP }}$; cells fired spontaneously at that level, whereas $\mathrm{E}_{\mathrm{IPSP}}$, by definition, falls below spike threshold. Second, recent work has shown that activating the primary afferents will disynaptically inhibit the geniculate (Lo and Sherman, 1994; Bal et al., 1995) via feedback from the perigeniculate (Friedlander et al., 1981; Dubin and Cleland, 1977) as well as the cortex. Thus, the absence of cortical hyperpolarization after shocks to the primary afferents, during the time when the geniculate would be silenced by the perigeniculate, suggests that withdrawal of thalamic input does not markedly influence the cortical membrane potential.

The results presented here indicate that inhibition in simple cells is postsynaptic and, therefore, mediated by synapses distinct from those that provide excitation. The excitation is laid out by thalamocortical inputs (Hubel and Wiesel, 1962; Tanaka, 1983, 1985; Alonso et al., 1996; Reid and Alonso, 1996; Ferster et al., 1996; Cai et al., 1997; Chung and Ferster, 1997; Table 1, this manuscript) and likely amplified by intracortical inputs (SaintMarie and Peters, 1985; Douglas et al., 1991; Ahmed et al., 1994; Hirsch, 1995; Cai et al., 1997; Chung and Ferster, 1997). Inhibition is largely, or perhaps wholly, provided by inhibitory neurons apparently driven by stimuli of the reverse contrast. This separation of excitation and inhibition may give the cortex a wider dynamic range in which to negotiate its inputs (Troyer et al., 1998).

\section{Interactions between excitation and inhibition}

To understand the synaptic interactions that work to reduce responsiveness to suboptimal stimuli, we examined the patterns of excitation and inhibition evoked by stimuli that crossed the border between subregions. Our results indicate that inhibition regulates excitatory input in two ways, by means of hyperpolarizing the membrane or by effectively changing firing threshold or rate.

\section{Net hyperpolarization}

In many instances the inhibition driven through one subregion opposed the excitation driven through the other so strongly that the net response was hyperpolarizing. This observation bears on previous work that advanced the idea of cross-orientation inhibition. Several studies have reported that a cross-oriented bar presented in the simple receptive field led to inhibition (Bishop et al., 1973; Morrone et al., 1982; Pei et al., 1994). Our results indicate that subfield antagonism alone may account for the suppressive action of an orthogonal bar. It also follows that the structure of the receptive fields of the presynaptic inhibitory neurons need not be the precise mirror images of their postsynaptic targets (Fig. $5 F$, see circuit). That is, the interneurons can be driven to fire by the same stimuli that effectively suppress the cells they contact. 


\section{Modulation of firing behavior}

A second, more subtle, action was revealed when the inhibition was too weak to hyperpolarize the membrane outright. Instead, the mild inhibition seemed to elevate slightly the level of somatic depolarization required to produce an action potential or to slow the rate of firing. In the cat auditory brainstem, intracellular responses to tonal stimuli also reveal a dissociation between somatic membrane voltage and spike threshold and rate (Rhode et al., 1983). Additionally, records from the turtle visual cortex show that temporal distribution of component IPSPs regulate the efficacy of depolarizing compound synaptic responses (Colombe and Ulinski, 1996; Mancilla and Ulinski, 1996). It is possible that the inhibition shunts somatic excitation before it spreads to the site where the full-blown spike is produced, presumably in the proximal axon (Colbert and Johnston, 1996). This scheme is plausible because excitatory synapses are normally distributed on the dendrites, whereas inhibitory synapses are dense around the soma and axon hillock (LeVay, 1973; Fairén et al., 1983; McGuire et al., 1984; Ahmed et al., 1994). Alternatively, the inhibition could elevate the threshold directly by increasing conductance at the zone of spike initiation (Colbert and Johnston, 1996). Although these effects are small at the level of a single cell, they may gain weight when propagated through the circuit. Different rates of firing influence the success of transmission across the synapse (Thomson and West, 1993; Allen and Stevens, 1994; Dobrunz and Stevens, 1997; Tsodyks and Markram, 1997) as well as the integration of inputs by the postsynaptic neuron (Bernander et al., 1991; Shadlen and Newsome, 1994; Colombe and Ulinski, 1996; Mancilla and Ulinski, 1996; Häusser and Clark, 1997; Mancilla et al., 1998).

To conclude, the spatial segregation of on and off responses in the simple receptive field has given the opportunity to study excitatory and inhibitory inputs separately and to examine the mechanisms of their interaction when recruited in various balance. Our aim is to apply what we have learned from simple cells to studies of synaptic integration at higher cortical levels.

\section{REFERENCES}

Ahmed B, Anderson JC, Douglas RJ, Martin KM, Nelson JC (1994) Polyneuronal innervation of spiny stellate neurons in cat visual cortex. J Comp Neurol 341: 39-49.

Allen C, Stevens CF (1994) An evaluation of causes of unreliability of synaptic transmission. Proc Natl Acad Sci USA 9:10380-10383.

Alonso JM, Usrey WM, Reid RC (1996) Precisely correlated firing in cells of the lateral geniculate nucleus. Nature 383:815-819.

Bal T, von Krosigk M, McCormick DA (1995) Synaptic and membrane mechanisms underlying synchronized oscillations in the ferret lateral geniculate nucleus in vitro. J Physiol (Lond) 483:641-663.

Berman NJ, Douglas RJ, Martin KAC, Whitteridge D (1991) Mechanisms of inhibition in cat visual cortex. J Physiol (Lond) 440:697-722.

Bernander O, Douglas RJ, Martin KM, Koch C (1991) Synaptic background activity influences spatiotemporal integration in single pyramidal cells. Proc Natl Acad Sci USA 88:11569-11573.

Bishop PO, Coombs JS, Henry GH (1973) Receptive fields of simple cells in the cat striate cortex. J Physiol (Lond) 231:31-60.

Blanton M, LoTurco JJ, Kriegstein AR (1989) Whole-cell recording from neurons in slices of reptilian and mammalian cerebral cortex. J Neurosci Methods 30:203-210.

Bonds AB (1989) Role of inhibition in the specification of orientation selectivity of cells in the cat striate cortex. Vis Neurosci 2:41-55.

Bullier J, Norton TT (1987) Comparison of receptive-field properties of $\mathrm{X}$ and $\mathrm{Y}$ ganglion cells with $\mathrm{X}$ and $\mathrm{Y}$ lateral geniculate cells in the cat. J Neurophysiol 42:274-291.

Cai D, DeAngelis GC, Freeman RD (1997) Spatiotemporal receptive field organization in the lateral geniculate nucleus of cats and kittens. J Neurophysiol 78:1045-1061.
Carandini M, Heeger D (1994) Summation and division by neurons in visual cortex. Science 264:1333-1336.

Carandini M, Heeger DJ, Movshon JA (1997) Linearity and normalization in simple cells of the macaque primary visual cortex. J Neurosci 17:8621-8644.

Chung S, Ferster D (1997) The size of thalamic input to simple cells of the visual cortex. Soc Neurosci Abstr 23:2059.

Cleland BG, Lee BB (1985) A comparison of visual responses of cat lateral geniculate nucleus neurones with those of ganglion cells afferent to them. J Physiol (Lond) 369:249-268.

Colbert CM, Johnston D (1996) Axonal action-potential initiation and $\mathrm{Na}^{+}$channel densities in the soma and axon initial segment of subicular pyramidal neurons. J Neurosci 16:6676-6686.

Colombe JB, Ulinski PS (1996) Temporal integration windows for neurons in the feedforward pathways of visual cortex. Soc Neurosci Abstr 22:284.

Crook JM, Kisvarday ZF, Eysel UT (1997) GABA-induced inactivation of functionally characterized sites in cat striate cortex: effects on orientation tuning and direction selectivity. Vis Neurosci 14:141-158.

DeAngelis GC, Robson JG, Ohzawa I, Freeman RD (1992) Organization of suppression in receptive fields of neurons in cat visual cortex. J Neurophysiol 68:144-163.

Debanne D, Shulz D, Fregnac Y (1998) Activity dependent on and off responses in cat visual cortical receptive fields. J Physiol (Lond) 508:523-548.

Dobrunz LE, Stevens CF (1997) Heterogeneity of release probability, facilitation, and depletion at central synapses. Neuron 18:995-1008.

Douglas RJ, Martin KAC, Whitteridge D (1988) Selective responses of visual cortical cells do not depend on shunting inhibition. Nature 332:642-644.

Douglas RJ, Martin KAC, Whitteridge D (1991) An intracellular analysis of the visual responses of neurones in cat visual cortex. J Physiol (Lond) 440:659-696.

Dubin MW, Cleland BG (1977) Organization of visual inputs to interneurons of lateral geniculate nucleus of the cat. J Neurophysiol 40:410-427.

Edwards FA, Konnerth T (1992) Patch-clamping cells in sliced tissue preparations. In Methods in Enzymology 207:208-222.

Edwards FA, Konnerth A, Sakmann B, Takahashi T (1989) A thin slice preparation for patch clamp recordings from neurones of the mammalian central nervous system. Pflügers Arch 414:600-612.

Fairén A, DeFelipe J, Regidor J (1983) Nonpyramidal neurons: general account in cerebral cortex: cellular components of the cerebral cortex, Vol 1, (Peters A, Jones EG, eds) pp 201-253. New York: Plenum.

Ferster D (1986) Orientation selectivity of synaptic potentials in neurons of cat primary visual cortex. J Neurosci 6:1284-1301.

Ferster D (1988) Spatially opponent excitation and inhibition in simple cells of the cat visual cortex. J Neurosci 8:1172-1180.

Ferster D, Jagadeesh B (1992) EPSP-IPSP interactions in cat visual cortex studied with in vivo whole-cell patch recording. J Neurosci 14:1262-1274.

Ferster D, Lindström S (1983) An intracellular analysis of geniculocortical connectivity in area 17 of the cat. J Physiol (Lond) 342:181-215.

Ferster D, Chung S, Wheat H (1996) Orientation selectivity of thalamic input to simple cells of cat visual cortex. Nature 380:249-252.

Friedlander MJ, Lin CS, Stanford LR, Sherman SM (1981) Morphology of functionally identified neurons in lateral geniculate nucleus of the cat. J Neurophysiol 46:80-129.

Gilbert CD, Wiesel TN (1979) Morphology and intracortical projections of functionally identified neurons in cat visual cortex. Nature 280:120-125.

Hagihara K, Tsumoto T, Sato H, Hata Y (1988) Actions of excitatory amino acid antagonists on geniculo-cortical transmission in the cat's visual cortex. Exp Brain Res 69:407-416.

Hamill OP, Marty A, Neher E, Sakmann B, Sigworth FJ (1981) Improved patch clamp technique for high resolution current recording from cells and cell free patches. Pflügers Arch 391:85-100.

Hausser M, Clark BA (1997) Tonic synaptic inhibition modulates neuronal output pattern and spatiotemporal synaptic integration. Neuron 19:665-678.

Heeger DJ (1992) Normalization of cell responses in cat visual cortex. Vis Neurosci 9:181-198.

Heggelund P (1981) Receptive field organization of simple cells in cat striate cortex. Exp Brain Res 42:82-98.

Heggelund P (1986) Quantitative studies of enhancement and suppres- 
sion zones in the receptive fields of simple cells in cat striate cortex. J Physiol (Lond) 373:293-310.

Hirsch JA (1995) Synaptic integration in layer 4 of the ferret visual cortex. J Physiol (Lond) 481:247-262.

Hirsch JA, Alonso JM, Reid RC (1995) Two dimensional spatial maps of excitation and inhibition in the simple receptive field. Soc Neurosci Abstr 21:21.

Hoffman KP, Stone J (1971) Conduction velocity of afferents to cat visual cortex: a correlation with cortical receptive field properties. Brain Res 32:460-466.

Horikawa K, Armstrong WE (1988) A versatile means of labeling: injection of biocytin and its detection with avidin conjugates. J Neurosci Methods 25:1-11.

Hubel DH, Wiesel TN (1961) Integrative action in the cat's lateral geniculate body. J Physiol (Lond) 155:385-398.

Hubel DH, Wiesel TN (1962) Receptive fields, binocular interaction and functional architecture in the cat's visual cortex. J Physiol (Lond) 160:106-154.

Humphrey AL, Weller RE (1988) Structural correlates of functionally distinct X-cells in the lateral geniculate nucleus of the cat. J Comp Neurol 268:448-468.

Humphrey AL, Sur M, Ulrich DJ, Sherman SM (1985) Projection patterns of individual $\mathrm{X}$ and $\mathrm{Y}$ cell axons from the lateral geniculate nucleus to cortical areas 17 and 18. J Comp Neurol 233:159-189.

Jones JP, Palmer LA (1987) The two-dimensional spatial structure of simple receptive fields in cat striate cortex. J Neurophysiol 58:1187-1211.

LeVay S (1973) Synaptic patterns in the visual cortex of the cat and monkey: Electron microscopy of Golgi preparations. J Comp Neurol 150:53-86.

LeVay S, Gilbert CD (1976) Laminar patterns of geniculocortical projection in the cat. Brain Res 113:1-19.

Lo FS, Sherman SM (1994) Feedback inhibition in the cat's lateral geniculate nucleus. Exp Brain Res 100:365-368.

Lorente de Nó R (1944) Cerebral cortex: architecture, intracortical connections, motor projections. In: Physiology of the nervous system (Fulton JF, ed), pp 291-325. London: Oxford UP.

Malinow R, Tsien RW (1990) Presynaptic enhancement shown by whole-cell recordings of long-term potentiation in hippocampal slices. Nature 346:177-180.

Mancilla JG, Ulinski PS (1996) Temporal structure of compound postsnaptic potentials in visual cortex. In: Computational neuroscience: trends in research (Bower J, ed), pp 227-232. San Diego: Academic.

Mancilla JG, Fowler M, Ulinski PS (1998) Responses of regular spiking and fast spiking cells in turtle visual cortex to light flashes. Vis Neurosci 15:979-993.

Mastronarde DN (1987) Two classes of single-input X-cells in cat lateral geniculate nucleus. I. Retinal inputs and the generation of receptivefield properties. J Neurophysiol 57:357-380.

McGuire B, Hornung JP, Gilbert CD, Wiesel TN (1984) Patterns of synaptic input of layer 4 of the cat striate cortex. J Neurosci 4:3021-3033.

Miller KD (1994) A model for the development of simple cell receptive fields and the ordered arrangement of orientation columns through activity-dependent competition between ON- and OFF-center inputs. J Neurosci 14:409-4041.

Morrone MC, Burr DC, Maffei L (1982) Functional implications of cross-orientation of cortical visual cells. Proc R Soc Lond B Biol Sci 216:335-354.

Movshon JA, Thompson ID, Tolhurst DJ (1978) Spatial summation in the receptive fields of simple cells in the cat's striate cortex. J Physiol (Lond) 283:53-77.

Nelson S, Toth L, Sheth B, Sur M (1994) Orientation selectivity of cortical neuron during intracellular blockade of inhibition. Science 265:74-77.

Ohzawa I, Sclar G, Freeman R (1982) Contrast gain control in the cat visual cortex. Nature 298:266-268.
Ohzawa I, DeAngelis GC, Freeman RD (1996) Encoding of binocular disparity by simple cells in the cat's visual cortex. J Neurophysiol 75:1779-1805.

Otis TS, De Koninck Y, Mody I (1993) Characterization of synaptically elicited GABAb responses using patch-clamp recordings in rat hippocampal slices. J Physiol (Lond) 463:391-407.

Palmer LA, Davis TL (1981) Receptive-field structure in cat striate cortex. J Neurophysiol 46:260-276.

Pare D, Shink E, Gaudreau H, Destexhe A, Lang E (1998) Impact of spontaneous synaptic activity on the resting properties of cat neocortical pyramidal neurons in vivo. J Neurophysiol 79:1450-1460.

Pei X, Vidyasagar TR, Volgushev M, Creutzfeldt OD (1991) Whole-cell recording and conductance measurements on cat visual cortex in vivo. NeuroReport 2:485-488.

Pei X, Vidyasagar TR, Volgushev M, Creutzfeldt OD (1994) Receptive field analysis and orientation selectivity of postsynaptic potentials of simple cells in cat visual cortex. J Neurosci 14:7130-7140.

Peters A, Payne BR (1993) Numerical relationships between geniculocortical afferents and pyramidal cell modules in primary visual cortex. Cereb Cortex 3:69-78.

Rall W (1977) Core conductor theory and cable properties of neurons. In: Handbook of physiology. The nervous system. Cellular biology of neurons. Sect 1, Vol 1, Part 1, pp 39-97. Bethesda, MD: American Physiology Society.

Reid RC, Alonso JM (1996) The precision of monosynaptic connections from the thalamus to visual cortex. Nature 378:281-284.

Rhode WS, Smith PH, Oertel D (1983) Physiological response properties of cells labeled intracellularly with horseradish peroxidase in cat dorsal cochlear nucleus. J Comp Neurol 213:426-447.

Saint Marie RL, Peters A (1985) The morphology and synaptic connections of spiny stellate neurons in monkey visual cortex (area 17): a Golgi-electron microscopic study. J Comp Neurol 233:213-235.

Sclar G, Freeman RD (1982) Orientation selectivity in the cat's striate cortex is invariant with stimulus contrast. Exp Brain Res 46:457-461.

Shadlen MN, Newsome WT (1994) Noise, neural codes and cortical organization. Curr Opin Neurobiol 4:569-579.

Sillito AM (1975) The contribution of inhibitory mechanisms to the receptive field properties of neurons in the striate cortex of the cat. J Physiol (Lond) 250:305-329.

Sillito AM (1992) GABA-mediated inhibitory processes in the function of the geniculo-striate system. Prog Brain Res 90:349-384.

Skottun BC, DeValois RL, Grosof DH, Movshon JA, Albrecht DG, Bonds AB (1991) Classifying simple and complex cells on the basis of response modulation. Vision Res 31:1079-1086.

Staley KJ, Otis TS, Mody I (1992) Membrane properties of dentate gyrus granule cells: comparison of sharp microelectrode and whole-cell recordings. J Neurophysiol 67:1346-1358.

Stühmer A, Roberts M, Almers W (1983) The loose patch clamp. In: Single channel recording (Sakmann B, Neher E, eds), pp. 123-132. New York: Plenum.

Tanaka K (1983) Cross-correlation analysis of geniculostriate neuronal relationships in cats. J Neurophysiol 49:1303-1318.

Tanaka K (1985) Organization of geniculate inputs to visual cortical cells in the cat. Vision Res 25:357-364.

Thomson AM, West DC (1993) Fluctuation in pyramid-pyramid excitatory postsynaptic potentials modified by presynaptic firing pattern and postsynaptic membrane potential using paired intracellular recordings in rat neocortex. Neuroscience 54:329-346.

Troyer TW, Krukowski A, Priebe NJ, Miller KD (1998) Contrastinvariant orientation tuning in cat visual cortex: feedforward tuning and correlation-based intracortical connectivity. J Neurosci 18:5908-5927.

Tsodyks MV, Markram H (1997) The neural code between neocortical pyramidal neurons depends on neurotransmitter release probability. Proc Natl Acad Sci USA 94:719-723.

Volgushev M, Pei X, Vidyasagar TR, Creutzfeldt OD (1993) Excitation and inhibition in orientation selectivity of cat visual cortex neurons revealed by whole-cell recordings in vivo. Vis Neurosci 10:1151-1155. 